\title{
A Simple Substrate Heater Device With Temperature Controller for Thin Film Preparation
}

\author{
G. Rendón ${ }^{1}$, P. Poot ${ }^{2}$, A.I. Oliva ${ }^{3}$, F.J. Espinosa-Faller*4 \\ 1,2,4 Universidad Marista de Mérida, Escuela de Ingeniería, \\ Periférico Norte Tablaje 13941, Mérida, Yucatán, 97300, México. \\ *fjespinosa@marista.edu.mx. \\ ${ }^{3}$ Centro de Investigación y de Estudios Avanzados del IPN, Unidad Mérida, \\ Departamento de Física Aplicada, Km. 6 Antigua Carretera a Progreso, \\ A.P. 73-Cordemex, 97310, Mérida, Yucatán México.
}

\begin{abstract}
A simple substrate heater and its temperature controller were designed and built in order to prepare thin films in a high vacuum deposition system. The substrate heater was elaborated with a glass-ceramic body and a molybdenum foil heater. The applied power and the temperature are regulated by a power controller board using a microcontroller programmed with a proportional-integrative-derivative algorithm. The heater/controller system was tested in a high vacuum deposition system and the results of its characterization at $100,200,300$ and $400{ }^{\circ} \mathrm{C}$ are presented. A variation in temperature better than $\pm 0.5^{\circ} \mathrm{C}$ was obtained for all the tested temperatures. An application of the substrate heater is demonstrated by evaporating gold thin films on heated glass substrates.
\end{abstract}

Keywords: substrate heater, temperature controller, vacuum thin film deposition.

\section{RESUMEN}

Se presenta el diseño y la fabricación de un calentador de sustratos con control de temperatura para preparar películas delgadas en un sistema de depósito de alto vacío. El calentador de sustratos fue elaborado usando vitrocerámica y una lámina de molibdeno como elemento calefactor. La energía aplicada y la temperatura del calentador de sustrato son controladas a través de una tarjeta controladora de potencia usando un microcontrolador programado con un algoritmo basado en un sistema de control proporcional-integral-derivativo. El sistema calentador/controlador propuesto fue evaluado a las temperaturas de $100,200,300$ y $400{ }^{\circ} \mathrm{C}$. El sistema proporciona una regulación de temperatura menor a $\pm 0.5{ }^{\circ} \mathrm{C}$ para todas las temperaturas evaluadas. La aplicabilidad del calentador de sustratos se demostró depositando películas delgadas de oro sobre sustratos de vidrio calentados.

\section{Introduction}

The properties of thin films grown by thermal deposition under high vacuum conditions depend on the temperature of the substrate, among other parameters. During growth, the vacuum evaporated material condenses on the substrate, and the further nucleation and growth of the formed film depends on the impinged energy at arrival and on the energy obtained from the substrate. Atom mobility produced by high temperatures, promotes a better crystalline structure and large grain sizes in polycrystalline materials [1].

High vacuum conditions and high temperatures during growth reduce the selection of the type of material to be used as substrate heater [2]. Contaminants can be introduced in the vacuum chamber by desorption and by the low vapor pressure of used materials. Besides, high temperatures can soften materials, changing the geometry of the components. Commercially available substrate heaters overcome these limitations at a high cost, including features such as large substrate diameter, substrate rotation, dual cooling/heating or designs which are inert to oxygen or corrosive atmospheres [3-6]. Depending on the applications, those features might be required; however, they are not included in the present design.

The automatic control of the temperature of a substrate heater is a requirement in order to obtain desirable physical properties of thin films. In this 
work, the design and implementation of a simple and low cost substrate heater and its temperature controller is presented. An application of the substrate heater is demonstrated by the deposition of gold thin films onto glass substrates in a high vacuum thermal evaporation system.

\section{Experimental}

\subsection{Substrate heater}

The design of the substrate heater was based on the idea that simplicity produces robust designs. Low power was also a requirement in order to avoid a substantial increment of temperature in the vacuum chamber during the thermal evaporation of the thin films. The chosen materials for the substrate heater were based mainly on their high vacuum properties and machinability, such that they can be manufactured with standard machines and tools.

The main part of the substrate heater (Fig. 1) was entirely made of Macor [7], a glass-ceramic and machinable material with excellent thermal characteristics: it can be continuously used at 800 ${ }^{\circ} \mathrm{C}$ with a peak temperature of $1000{ }^{\circ} \mathrm{C}$. Its thermal expansion coefficient matches most metals, exhibits negligible porosity and possesses low mechanical deformation. The high dimensional stability of Macor at high temperatures and low outgassing rates makes it a useful material for high and ultrahigh vacuum applications. The substrate to be heated is mounted in direct contact to a circular copper block with a diameter of $17.5 \mathrm{~mm}$ made of oxygen free-copper, purity $99.99 \%$. A threaded cap made also of Macor is fixed to the substrate heater by pressing the substrate to the copper block. A thermocouple is inserted from one side of the threaded cap into a small cavity in the copper block in order to monitor the temperature as close as possible to the substrate. This configuration provides thermal contact and temperature homogenization due to the high thermal conductivity of the copper.

The heating element was implemented with high purity molybdenum (99.95\%) foil in order to heat the copper block. A rectangular $0.051 \mathrm{~mm}$-thick Mo foil of $6.5 \times 41.5 \mathrm{~mm} 2$ was used and assembled as shown in Fig. 1. Two electrodes made of stainless steel press and support the substrate heater in direct contact with the Mo heating element. The assembly, inside the vacuum chamber, is shown in Fig. 2. This design makes the substrate holder easy to install and to replace.
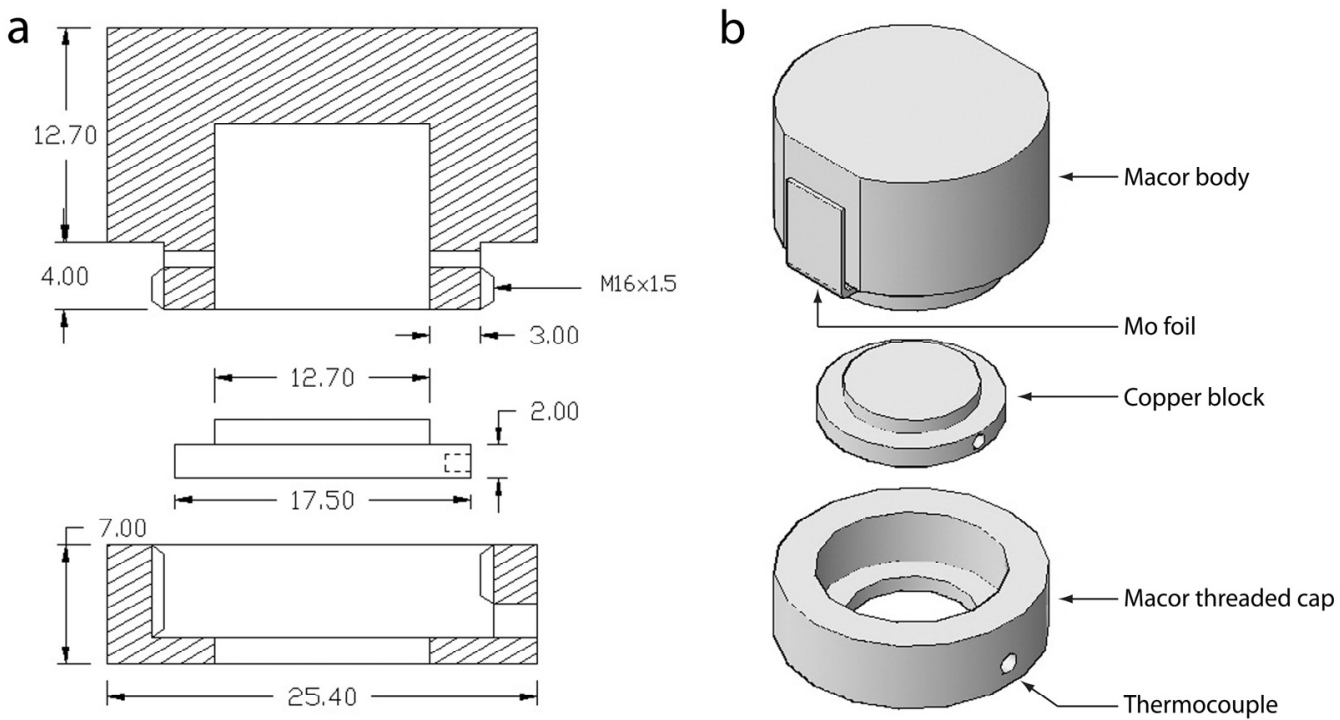

Figure 1. Substrate heater components (dimensions in $\mathrm{mm}$ ).

a) Transversal section. b) Exploded view of the assembly. 


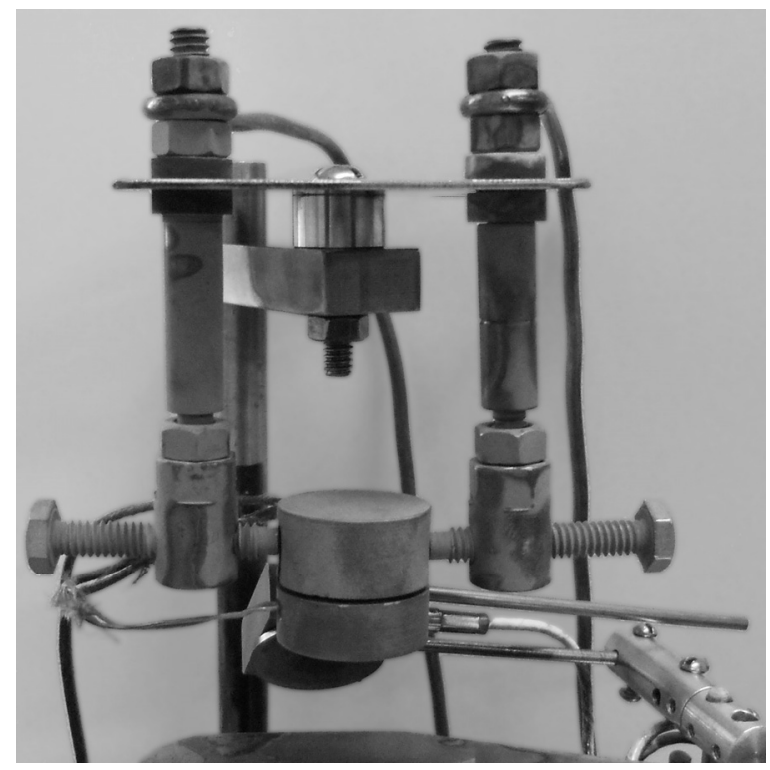

Figure 2. Substrate heater inside the vacuum chamber.

\subsection{Temperature controller}

The control and stability of temperature during film growth is also a requirement for film reproducibility. In order to regulate the temperature of the substrate heater, a temperature controller was developed. The controller device contains a microcontroller that regulates the power output of a $200 \mathrm{~W}$ electric transformer. The microcontroller reads the value of the setpoint (target temperature) from an adjustable rotary knob, and the substrate heater temperature from a K-type thermocouple. A proportional-integral-derivative (PID) algorithm regulates the power output of the electric transformer and thus, the temperature of the substrate heater [8].

The electronic circuit of the controller is shown in Fig. 3. The secondary winding of the transformer (bottom of Fig. 3) provides a low voltage and high current output which is directly connected to the heating element. The primary coil of the transformer is connected to the $127 \mathrm{VAC}$ line and is driven by a snubberless triac. The electrical power applied to the heating element is controlled by registering the time when the alternating voltage crosses the zero voltage point and waiting for a certain time, calculated by the PID algorithm, to activate the triac into a high conduction state. This allows flowing current to the primary coil of the transformer from the activation time of the triac until the next zero crossing of the AC line voltage. In this way, a short delay-time generates a high power output and a large delay-time generates a small power output. The maximum time for activating the triac needs to be the time of halfcycle of the AC line which is $\sim 8.3 \mathrm{~ms}$, in order to capture the next zero crossing of the power line and start the cycle again.

The microcontroller device used for the control of the temperature is the ATtiny 13 from Atmel Corp. Two 10-bit analog-digital converter (ADC) lines (into the device) were used to read the setpoint and the output signal from the thermocouple conditioner (AD597 from Analog Devices Inc.). The difference between the setpoint and the thermocouple voltage produces the error value used in the PID algorithm. Due to the digital nature of the microcontroller and the 10 bits of the analog to digital converter, the error signal (between 0 and 5 volts) is converted to an integer value between zero and 1023. For registering the zero crossing of the $A C$ line, the output of the rectified 12 VAC transformer (Fig. 2) is limited at $5 \mathrm{~V}$ peak to peak by a variable resistor. This signal is connected to a digital input of the microcontroller which generates an interrupt in the software when the logic signal 


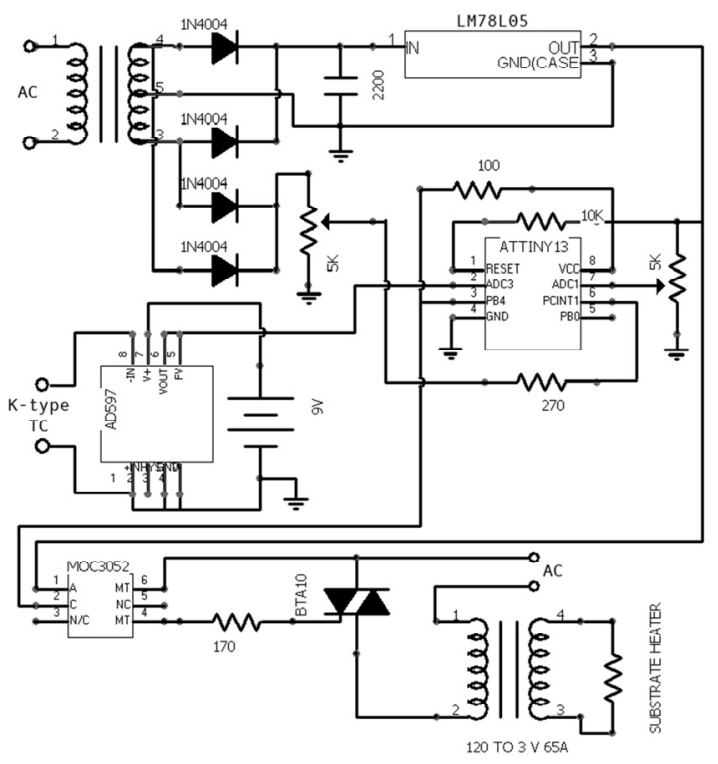

Figure 3. Electronic diagram of the temperature controller.

changes from 0 to 1 value. The digital pulse output signal from the microcontroller is used to drive a photo-triac (MOC3052 from Fairchild Semi.) which in turn drives the snubberless power triac (BTA10 from ST micro.). This configuration provides optical insulation between the low-voltage microcontroller and the high-voltage $\mathrm{AC}$ signal.

The control of the temperature of the substrate heater is performed, as mentioned before, by calculating an error signal coming from the difference between the setpoint and the output of the thermocouple signal. The lapsed time (delaytime, DT) in activating the triac to a high conduction state, after the zero crossing of the voltage, is calculated incorporating the PID equation according to

$$
D T=T D C\left(M P-\left(K_{p} e+K_{i} \int e d t+K_{d} \frac{d e}{d t}\right)\right)
$$

In this equation, $M P$ is the maximum power constant implemented as a 10-bit integer between zero and 1023, $K_{p}, K_{i}$ and $K_{d}$ are the proportional, integral and derivative calibration parameters, $e$ is the error-voltage or difference between the setpoint (SP) and the thermocouple voltage or process value (PV) and TDC is a constant to convert the integer value between 0 and 1023 to time between 0 and 8.3 $\mathrm{ms}$. Although this equation can be readily implemented in the algorithm, in order to promote stability in the derivative term, a change of variable is used. We changed the error variable in the derivative term by the process value by noticing that $e=S P-P V$. In this form, the differential term becomes $K_{d} \frac{-d P V}{d T}$. In addition the value of the integral term was limited in order to avoid the "windup" of this term [8].

The algorithm, shown as a flow diagram in Fig. 4, consists of an infinite loop that is waiting for an interruption. When an interruption happens, indicating a zero crossing of the $A C$ line, the program activates the triac device at the specified amount of $D T$. Every 1200 interrupts (ten seconds) the program recalculates a new $D T$ value. The software was developed entirely in the $C$ programming language using the AVR-GCC compiler. Source code of the program is available upon request. 


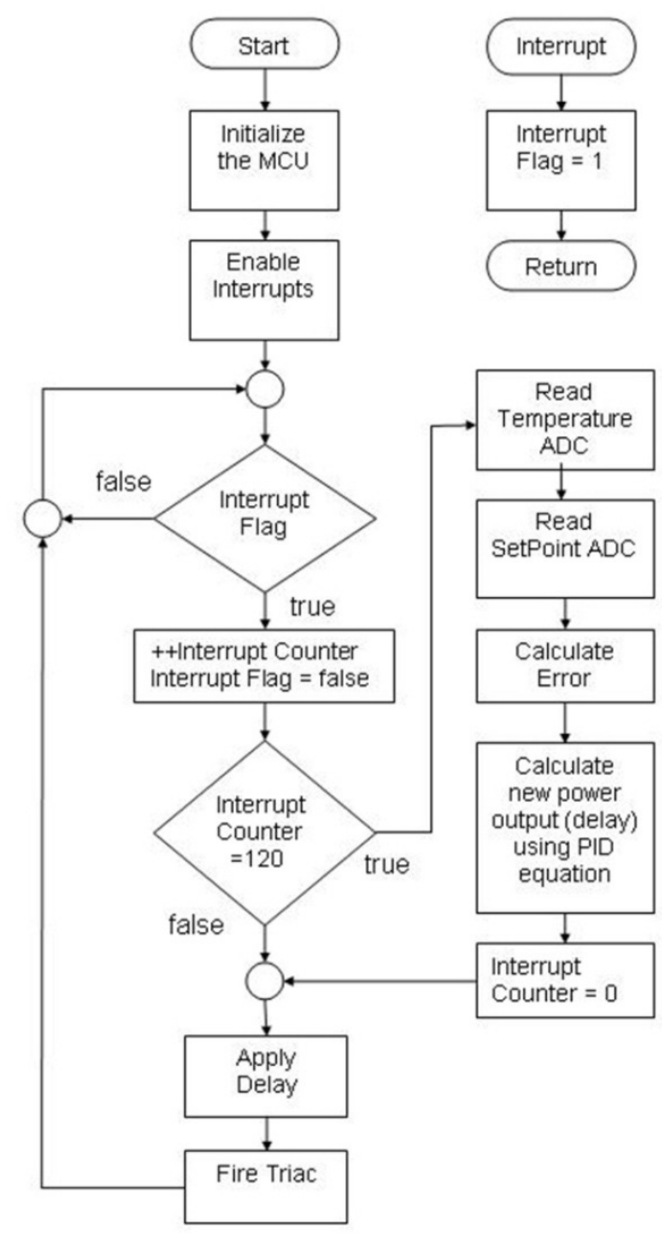

Figure 4. Flow diagram of the temperature controller.

\subsection{System calibration}

The voltage output from the AD597 thermocouple conditioning integrated circuit was divided by the factor $0.10 \mathrm{~V} /{ }^{\circ} \mathrm{C}$ in order to get the readings in ${ }^{\circ} \mathrm{C}$. This initial temperature value was shifted to the calibrated value by comparing its value to the measurement of a high accuracy and resolution $\mathrm{HH} 42$ thermistor thermometer from Omega Engineering in thermal equilibrium at room temperature. We note that unavoidable temperature gradients are going to be present between the thermocouple and the temperature at the surface of the substrate. For a precise surface temperature measurement, it is recommended to use a high precision calibrated infrared thermometer.
The temperature controller was programmed with an arbitrary initial value for the proportional term ( $\left.K_{p}\right)$, and zero both for integrative $\left(K_{i}\right)$ and derivative $\left(K_{d}\right)$ terms. The initial temperature to be controlled was $100{ }^{\circ} \mathrm{C}$ and the plot of temperature vs. time was evaluated until a satisfactory value of the proportional term with a substrate temperature within $10 \%$ of the setpoint temperature was obtained. Both, the setpoint and the process temperature, were monitored using two analog inputs of a National Instruments PCl6023E card.

The initial parameters of the integrative term were set inspired in the Ziegler-Nichols method adapted to the integer arithmetic used in the software of the microcontroller [9]. The final integrative term was set by observing the behavior of the oscillations around the target value until their amplitudes decrease with time and a low overshoot was obtained. Finally, the derivative term was included and the parameters were refined based on the system behavior until a stable temperature with minimum oscillations was obtained.

\subsection{Thin film deposition}

The applicability of the substrate heater in thin film processing was demonstrated by thermally evaporating gold thin films. Corning 2749 glass was used as substrate. Before deposition, the glass substrates were cleaned with non-abrasive soap, chemically etched for 30 minutes in a $\mathrm{H}_{2} \mathrm{O}_{2}: \mathrm{H}_{2} \mathrm{SO}_{4}$ (1:3 ratio) solution, rinsed with distilled water, and finally, cleaned with methanol in an ultrasonic bath. The vacuum chamber was evacuated to pressure of $\sim 5 \times 10^{-5}$ Torr and a 2 $\mathrm{nm}$-adhesive layer of chromium was evaporated.

The gold thin films were deposited by maintaining the glass substrate temperature at $300 \pm 2{ }^{\circ} \mathrm{C}$ and evaporating metallic gold (99.99\% purity) on them until thicknesses of 25,50 and $75 \mathrm{~nm}$ were achieved with $\sim 1.5 \AA / s$ as a rate deposition. Thin film thickness was monitored using a quartz crystal monitor from Sigma Instruments (SQM-242). As a reference, a gold film of $50 \mathrm{~nm}$ was grown on a glass substrate at room temperature $\left(25^{\circ} \mathrm{C}\right)$. The surface morphology of the films was analyzed using an atomic force microscope (AFM/STM 
Ambios Universal). The surface roughness was estimated from the Ambios-software and the grain size from the AFM images [10].

\section{Results and discussion}

The temperature controller was tested at 100 , 200,300 and $400{ }^{\circ} \mathrm{C}$. A plot of the controlled temperature vs. time is shown in Fig. $5 a$ and its corresponding current and voltage rms-values applied to the heating element is shown in Fig. 5b. As can be observed, the controlled temperatures present small oscillations around the setpoint until a stable temperature is reached. The standard deviation of the temperature around each setpoint, after 15 minutes of operation, was $0.20,0.27,0.29$ and $0.31{ }^{\circ} \mathrm{C}$ for $100,200,300$ and $400{ }^{\circ} \mathrm{C}$, respectively. This indicates a variation in the control of the temperature better than $0.4 \%$ over the range of temperature analyzed.
The AFM images of the gold films prepared under high vacuum conditions with different thicknesses and substrate temperatures are shown in Fig. 6 . Results of the analysis of the gold films are shown in Table 1. The surface roughness increases with thickness at $300{ }^{\circ} \mathrm{C}$ of the substrate temperature while the grain size remains constant at $150 \mathrm{~nm}$ for 25 and $50 \mathrm{~nm}$ of film thickness. For thickness of 75 $\mathrm{nm}$, the grain size increased to $175 \mathrm{~nm}$. Differences of films grown on substrates at room temperature (25 ${ }^{\circ} \mathrm{C}$ ) and heated at $300{ }^{\circ} \mathrm{C}$ can be observed by comparing the rms- roughness and the grain size. An increment of $22 \%$ in roughness and a decrement of $28 \%$ in grain size were found for the film deposited at room temperature, in comparison with the film grown at $300{ }^{\circ} \mathrm{C}$. Besides, the effect of the substrate temperature during growth is to increase the grain size, as confirmed with AFM images $B$ and $C$ in Figure 6. These results are consistent with the expected benefits of the substrate temperature effect over the characteristics of thin films.

a)

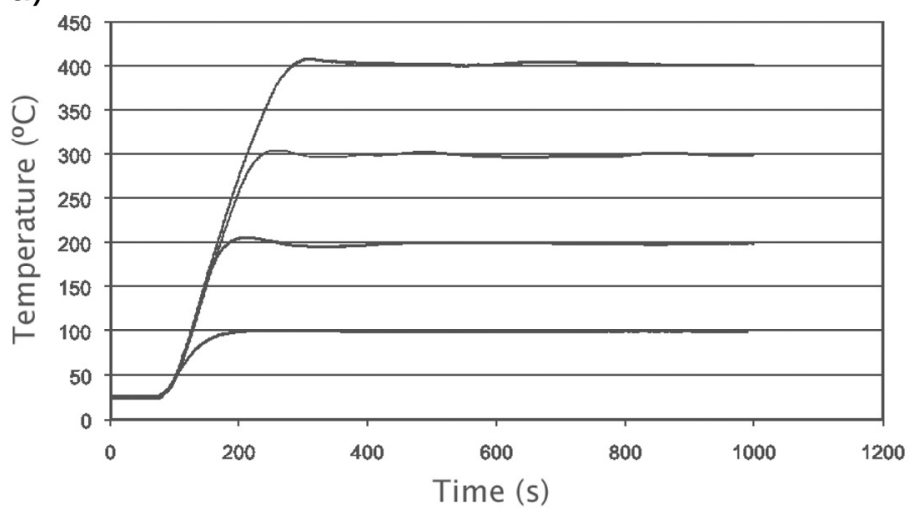

b)

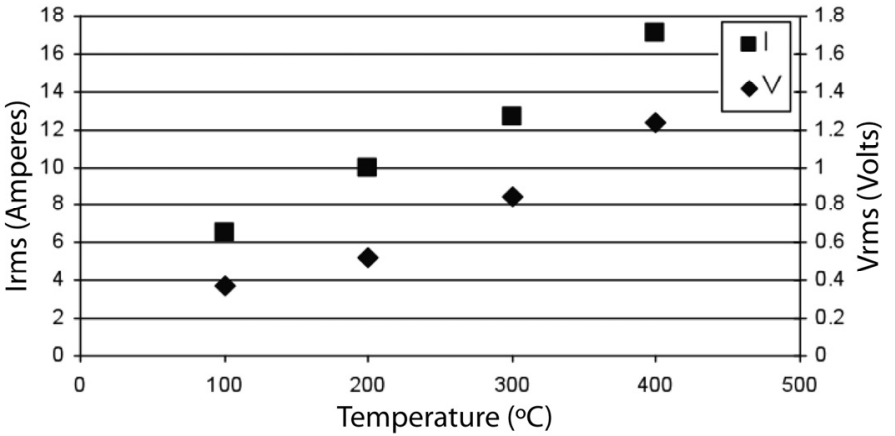

Figure 5. (a) Plot of the controlled temperatures vs. time of the substrate heated at $100,200,300$ and $400{ }^{\circ} \mathrm{C}$ as setpoint temperature. The temperature controller was turned on after $50 \mathrm{~s}$ to display the baseline.

(b) Rms-values of the electrical current and voltage applied to the substrate heater after a stable temperature is reached. 

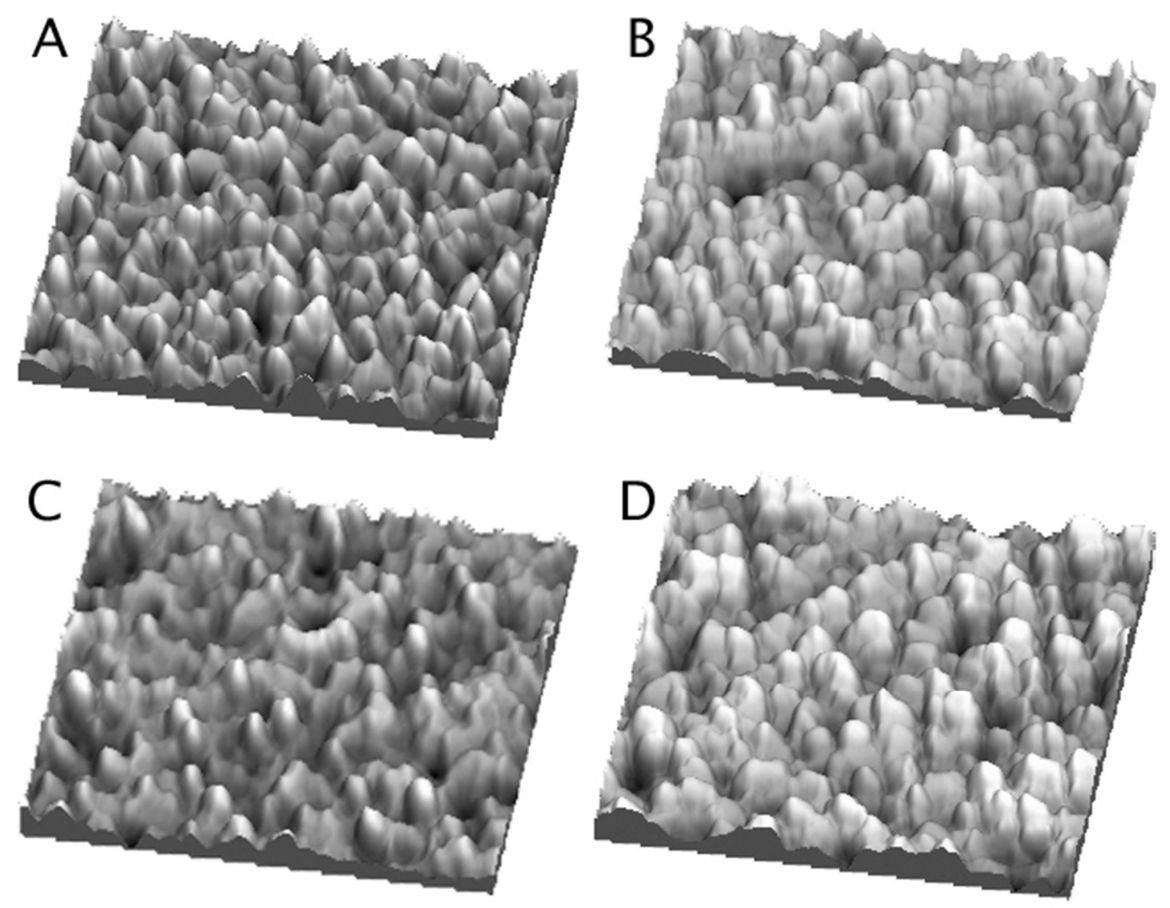

Figure 6. Scanning force microscopy images of the gold thin film samples: A) $\left.25 \mathrm{~nm} @ 300^{\circ} \mathrm{C}, \mathrm{B}\right) 50 \mathrm{~nm} @$ $\left.300{ }^{\circ} \mathrm{C}, \mathrm{C}\right) 50 \mathrm{~nm} @ 25^{\circ} \mathrm{C}$, and D) $75 \mathrm{~nm} @ 300^{\circ} \mathrm{C}$.

\begin{tabular}{|c|c|c|c|c|c|}
\hline Sample & $\begin{array}{c}\mathrm{Au} \\
(\mathrm{nm})\end{array}$ & $\begin{array}{c}\mathrm{Cr} \\
(\mathrm{nm})\end{array}$ & $\begin{array}{c}\text { Substrate Temperature } \\
\left({ }^{\circ} \mathrm{C}\right)\end{array}$ & Rms-roughness $(\mathrm{nm})$ & $\begin{array}{c}\text { Grain size } \\
(\mathrm{nm})\end{array}$ \\
\hline $\mathrm{A}(\mathrm{P} 6)$ & 25 & 2 & 300 & 3.8 & 150 \\
\hline $\mathrm{B}(\mathrm{P} 1)$ & 50 & 2 & 300 & 7.4 & 150 \\
\hline $\mathrm{C}(\mathrm{P} 3)$ & 50 & 2 & 25 & 9.4 & 92 \\
\hline $\mathrm{D}(\mathrm{P} 5)$ & 75 & 2 & 300 & 10.7 & 175 \\
\hline
\end{tabular}

Table 1. Gold thin films characteristics after grown at different thickness and substrate temperatures. 


\section{Conclusions}

The substrate temperature plays an important role on the physical properties during thin films preparation. Its precise control can help to understand the existent relation between the films growth parameters and their properties. Heating the substrate in a controlled way is a technique used for growing thin films with variable grain sizes and surface morphology. The substrate heater and the temperature controller discussed here presented high stability with temperature variations minor than $\pm 0.4 \%$ when were heated in the range between $100{ }^{\circ} \mathrm{C}$ and $400{ }^{\circ} \mathrm{C}$.

The proposed design provides simple and low cost devices useful for thin film deposition. The main estimated costs being the time to machine the substrate heater made of Macor and the time to develop the software. However, as mentioned before, the software can be obtained from the authors at no cost.

The temperature controller and substrate heater system was used for growing gold thin films. It was shown that at high substrate temperatures, such as $300{ }^{\circ} \mathrm{C}$, the gold films exhibit larger grain size and lower surface roughness than gold films grown on substrates without heating.

\section{References}

[1] Sree Harsha K.S. Principles of physical vapor deposition of thin films. Elsevier, 2006.

[2] Kohl W.H., Handbook of materials and techniques for vacuum devices, AIP Press, 1995.

[3] Clark J. C., Maria J.P., Hubbard K. J., and Schlom D. $\mathrm{G}$. An oxygen-compatible radiant substrate heater for thin film growth at substrate temperatures up to $1050^{\circ} \mathrm{C}$,

Rev. Sci. Instrum. 68, 2538 (1997); doi:10.1063/1.1148156.

[4] Márquez-Herrera A., Hernández-Rodríguez E., CruzJáuregui, M.P., Zapata-Torres, M. y Zapata-Navarro, A. Calentador de sustratos compacto y de bajo costo para tratamiento térmico in situ de películas delgadas depositadas por rf-sputtering, Rev. Mex. Fis. Vol. 56 (1), (2010), pp. 85-91.

[5] Campion, R., Ormson, R.G., Bashford, C.A. and King, P.J., Design and performance of a reliable and low cost substrate heater for superconducting thin film deposition, Vacuum, 46 (2), (1995) pp. 195-197.

[6] Rousseau B., De Barros D., La Manna J., Weiss F., Duneau G., Odier P., De Sousa Meneses, D., Auger I., Melin P. and Echegut P. Resistive substrate heater for film processing by spray pirólisis, Rev. Sci. Instrum. 75 (9), (2004) pp. 2884-2886.

[7] Macor is a registered trademark of Corning Inc. Corning, N.Y. http://www.corning.com/docs/specialtyma terials/pisheets/Macor.pdf, 2011.

[8] Ang K.H., Chong G.C.Y. and Li Y. PID control system analysis, design, and technology. IEEE Transactions on Control Systems Technology, 13 (4), (2005) pp. 559-576.

[9] J. G. Ziegler and N. B. Nichols. Optimum settings for automatic controllers. Trans. ASME, 64 (1942) pp. 759-768.

[10]Ambios Q_Scope_Series_USPM_and_Accessories Brochure; http://ambios.ru/files/u1/Q_Scope_Series_US PM_and_Accessories_Brochure.pdf. June 2011. 